\title{
Dynamic Strategies and Management of Focusing Devices
}

\author{
Tsutomu Harada ${ }^{1}$ \\ ${ }^{1}$ Graduate School of Business Administration, Kobe University, Japan \\ Correspondence: Tsutomu Harada, Graduate School of Business Administration, Kobe University, 2-1 Rokkodai, \\ Nada, Kobe 657-8501, Japan. Tel: 81-78-803-6957. E-mail: harada@people.kobe-u.ac.jp
}

Received: March 7, 2014 Accepted: April 28, 2014 Online Published: May 27, 2014

doi:10.5539/jms.v4n2p22 URL: http://dx.doi.org/10.5539/jms.v4n2p22

\begin{abstract}
This paper examines how dynamic strategies and underlying focusing devices lead to dynamic competitive advantage. Our methodology is an analysis based on the simple mode of focusing device and innovation. We show that quality-improving and cost-reducing strategies are facilitated under a productivity-based pricingscheme, while a hybrid strategy is favoured by having a marginal productivity-based pricing scheme as the underlying focusing device of innovation. We also argue that a hybrid strategy achieves dynamic efficiency, so that cost-reducing and quality-improving strategies should converge towards ahybrid strategy over time, to attain dynamic competitive advantage. The implications of these results are threefold. First, the firm should determine the appropriate direction of innovationtrajectories, rather than a competitive position. Second, the firm should identify its current focusing device and examine whether it is congruent with the desired dynamic strategy. Third, over the long term, the firm should adopt a hybrid strategy. The value of this paper is significant as it provides the formal model of dynamic strategies.
\end{abstract}

Keywords: dynamic strategies, focusing devices, productivity-based pricing scheme, marginal productivity-based scheme, strategic convergence, cost-reducing strategy, quality-improving strategy, hybrid strategy

\section{Introduction}

What is strategy? How does competitive strategy contribute to sustainable competitive advantage? These questions, first raised by Porter (1980), have been the subject of much discussion by strategic management scholars, resulting in three major paradigms regarding the sources of competitive advantage. The positioning approach (Porter, 1980) emphasizes the actions a firm can take to create economic rents. The rents flow from the firm's position in the industry vis-à-vis competitors and suppliers, that somehow impedes the competitive forces in either factor or product markets.

Another paradigm, called the resource-based view (Wernerfelt, 1984), underscores firm-specific capabilities and assets as the fundamental determinants of competitive advantage. In contrast to the positioning approach, the resource-based view put more emphasis on the firm-level idiosyncrasy of resources rather than the industry-level excludability of competitive forces. Thus, according to this approach, competitive advantage is built upon the substratum of the firm-specific capabilities and assets.

Teece, Pisano and Shuen (1997) extended this approach to encompass the acquisition of skills and learning. This extension was a logical necessity because innovation becomes a fundamental strategic issue when control over scarce resources is the source of competitive advantage. Their dynamic capabilities approach addressed the issue of how combinations of capabilities and assets can be developed, deployed, and protected. In other words, this approach brought a dynamic perspective into the static resource-based view.

The dynamic capabilities approach has since attracted increasing attention within the management literature (see Barreto, 2010, for survey). However, subsequent developments along this line of research remain informal so that the dynamic capabilities approach, though it seems promising, has not succeeded in coming up with more specific propositions and implications regarding the dynamics of competitive advantage from the firm's perspective. Thus, Williamson (1999) posed two related concerns about this approach, i.e., that there are (1) obscure and often tautological definitions of key terms and (2) failures of operationalization. 
The purpose of this paper is to develop a formal model of dynamic strategies and underlying innovation mechanisms, and reveal how different dynamic strategies are related to focusing devices and competitive advantages. Instead of relyingon the elusive concept of dynamic capabilities, this paper emphasizes and substantiates innovation trajectories, which are referred to as dynamic strategies in this paper. We examine the relative dynamic efficiency of dynamic strategies in relation to focusing devices, and draw managerial implications.

The rest of the paper is organized as follows. Section 1 describes a conceptual framework of dynamic strategies and Section 2 develops the formal model of focusing devices that underlie dynamic strategies. Section 3 examines the optimal relationship between dynamic strategies and focusing devices. Finally, we present our conclusions.

\section{Conceptual Framework of Dynamic Strategies}

\subsection{Dynamic Strategies}

According to Porter (1996), strategy is defined as "the creation of a unique and valuable position, involving a different set of activities." This definition of strategy refers to a static choice of a position within the industries in which the firm competes. In contrast, we define dynamic strategies as innovation trajectories of the firm (Note 1), with emphasis on their direction and the underlying innovation probabilities.

In Figure 1, the competitive space is specified by two axes: quality and cost advantage. A consumer chooses a bundle of these two properties of the product from the set of available alternatives. Its utility is assumed to be well-behaved and the profits of the firm are in proportion to the utility level achieved by its product.

Suppose the current position of the firm is A in this competitive space. Then, if innovation of this firm moves in the north-west direction, that is, line a, the firm improves quality at the expense of cost advantage. By contrast, if the firm pursues the south-east direction of innovation, $b$, the firm engages in cost-reducing innovation, trading off against quality. The arrow pointing to the north-east of c implies simultaneous pursuit of both quality improvement and cost reduction.

The dynamic strategies corresponding to these innovation trajectories in the competitive space fall into three generic types. These are (1) quality-improving, (2) cost-reducing, and (3) hybrid strategies. The differences depend on the direction of the innovation trajectory from the current standpoint A, as is shown in Figure 2. Thus, while the competitive strategy bears upon the current position of the firm, dynamic strategies refer to the direction of innovation trajectories conditional upon the current position.

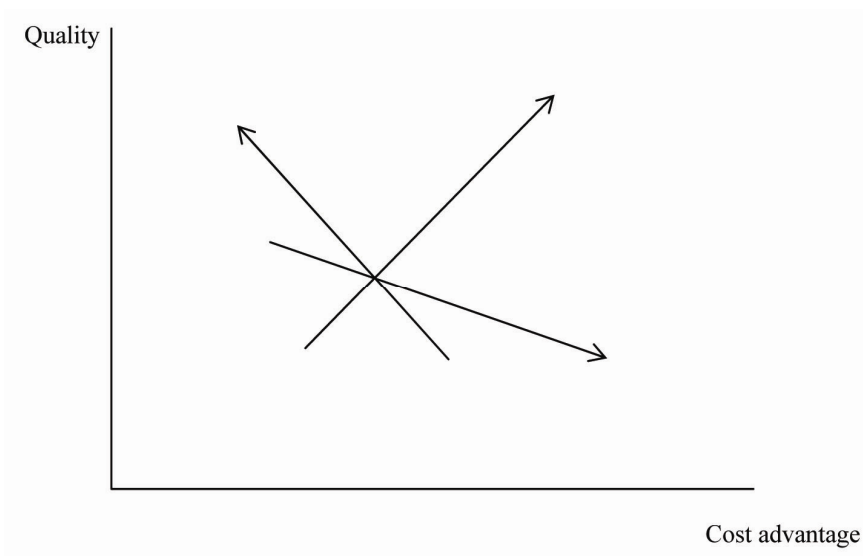

Figure 1. Innovation trajectory and dynamic strategies 


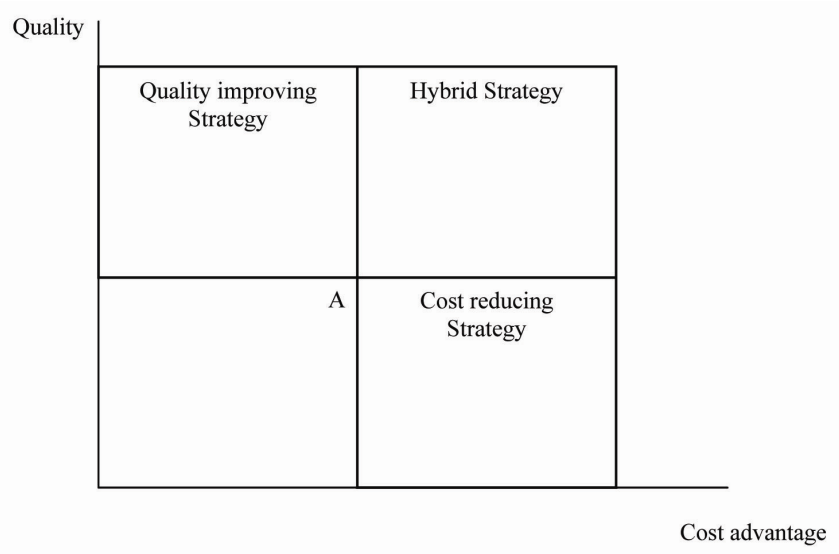

Figure 2. Three types of dynamic strategies

The quality-improving and cost-reducing strategies seem to correspond to Porter's (1980) generic strategies of differentiation and cost leadership, respectively. The hybrid strategy could also be associated with Porter's stuck-in-the-middle strategy, which pursues both differentiation and cost leadership simultaneously. However, these apparent relationships do not always hold, because competitive advantage depends on the relative position of the firm with respect to its competitors. For example, even if all firms pursue hybrid strategies, the eventual configuration of strategic positions could still be divided into differentiation, cost leadership, and stuck-in-the-middle because these generic strategies refer to relative, rather than absolute, positions.

\subsection{Innovation Probability Maximization}

To see this more clearly, Figure 3 illustrates innovation trajectories and the resulting shifts in competitive advantages. Suppose at time T, the position of firm A provides more competitive advantage than that of firm B because $U_{A}>U_{B}$, where $U$ represents the isoprofit curve. However, at time $\mathrm{T}+1$, innovation trajectories shift competitive advantages from firm A to firm B, despite the fact that both firms pursue hybrid strategies.

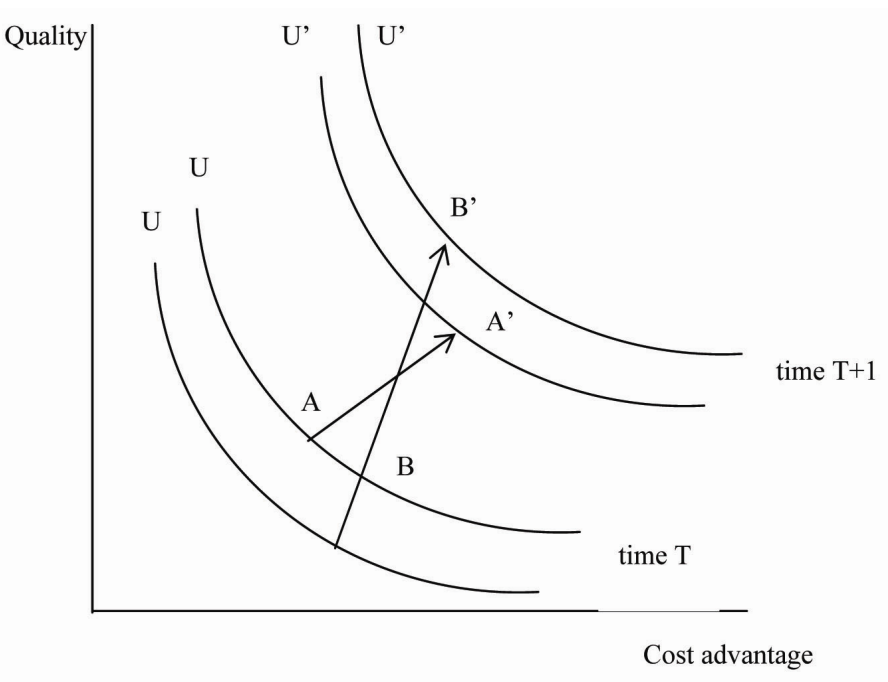

Figure 3. Shifts in competitive advantages and innovation trajectories

Clearly, the change in competitive advantage hinges critically on the magnitude of innovation. Of course, innovations reflect not only purposive R\&D efforts and capabilities but also some luck. Hence, the leapfrogging of firm B in Figure 3 might be attributed to pure luck. Indeed, a firm with the highest innovation probability does not always win a one-shot innovation game. Under repeated game settings, however, the firm will win more games than its competitors because of the law of large numbers. Thus, although competitive advantage might be 
hard to sustain in environments of rapid technological change, it could be acquired many times over in a repeated competition, by maximizing innovation probability. Therefore, dynamic strategies should be aiming not for sustainability of competitive advantage but rather resilience to competitive disadvantage, especially under conditions of highly uncertain and recurrent competition.

From the ex-ante perspective at time $\mathrm{T}$, the importance of building resilience suggests that the firm should maximize the innovation probability underlying the innovation trajectory that is to be realized at time $\mathrm{T}+1$.

\subsection{Strategic Convergence towards Hybrid Strategy}

While our three generic dynamic strategies - quality-improving, cost-reducing, and hybrid - show mutually exclusive directions of innovation, each dynamic strategy requires shifts towards a hybrid strategy at some point in the future, under the assumption of a well-behaved utility of a consumer. For example, in Figure 4, the quality-improving strategy of $A B$ is inferior to the hybrid strategy of $A^{\prime} A^{\prime}$ because $U^{\prime}>U$ holds. Indeed, this figure indicates that both positions of $\mathrm{A}$ and $\mathrm{B}$ provide the same utility to the customer. Paradoxically, if the quality-improving innovation continues from A to B, its competitiveness remains the same, whereas if it stops somewhere before reaching B, the firm improves its competitive advantage. However, as long as the firm stays in the trajectory of $\mathrm{AB}$, it cannot gain competitive advantage over competitors in AA'.

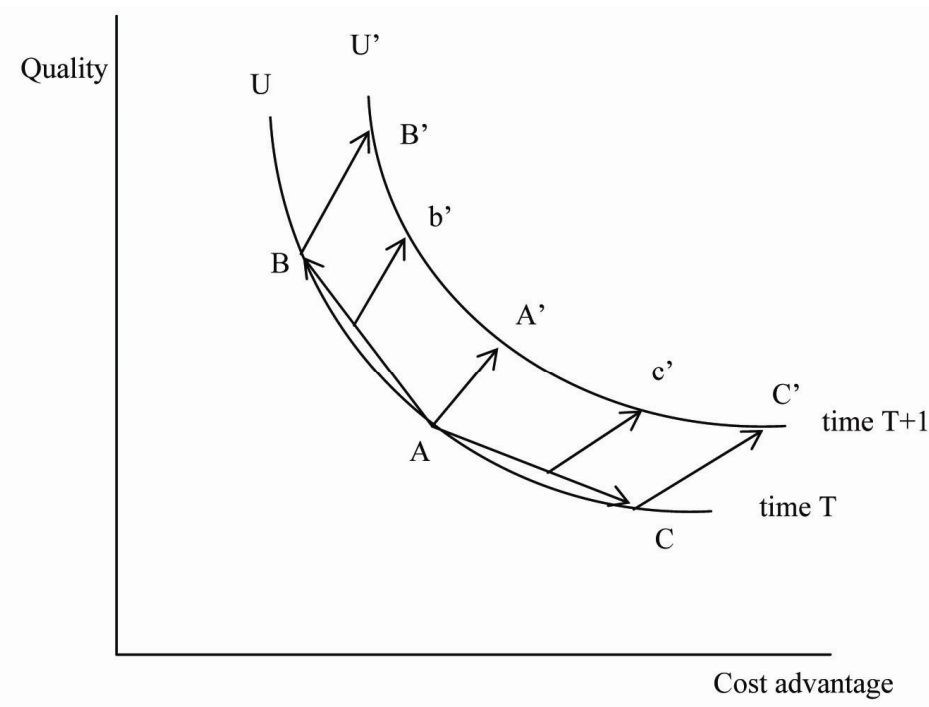

Figure 4. Shifts in dynamic strategies

To avoid this undesirable situation, the firm with the quality-improving strategy must shift, at some point in time, towards a hybrid strategy to compete with competitors in position A'. The same is true for the firm pursuing the cost-reducing strategy. These shifting points should be somewhere between $\mathrm{A}$ and $\mathrm{B}$ and between $\mathrm{A}$ and $\mathrm{C}$. In Figure 4, the firm should take either the path of Abb' or Acc'. In other words, as long as at least one firm chooses a hybrid strategy, other firms should follow the same strategy in future so as not to be driven out of competition.

Thus, all dynamic strategies are predicted to eventually converge to a hybrid one. In static competition, according to Porter (1980), the stuck-in-the-middle position, between differentiation and cost leadership, is more likely to lead to competitive disadvantage. However, dynamic competition over innovation trajectories necessitates the simultaneous improvement of both quality and cost advantage, leading to convergence on a hybrid strategy.

This difference between static and dynamic competition arises owing to the presence of innovation. Innovation enables the firm to eliminate the current trade-offs between quality and cost advantage and realize new trade-offs in an improved technology frontier. By contrast, the use of a given innovation requires "making trade-offs in competing" (Porter, 1996). Therefore, strategic goals must distinguish between static and dynamic strategies. In static competitive strategies, the goal is to choose the optimal position from the trade-offs, whereas in dynamic strategies, the goal is to eliminate current trade-offs by using a hybrid strategy. In other words, in the short term, 
a hybrid strategy (stuck-in-the-middle) dies and pure strategies (differentiation and cost leadership) survive. In the long run, all pure strategies (quality-improving and cost-reducing) die and only the hybrid one survives.

\section{The Model of Focusing Device}

If innovation probability and innovation trajectories play an important role in gaining dynamic efficiency, then what affects the direction of innovation trajectories and how is the innovation probability maximized over time? To answer these questions, we adopt a methodology of model, rather than empirical, analysis because the latter requires underlying theories and hypotheses. In this paper, we focus our attention on a model analysis of focusing devices and derive its theoretical predictions and implications regarding the direction of innovation trajectories and innovation probabilities. While we believe that our results could be consistent with empirical evidence, this consideration will have to wait for future studies.

The focusing device is the innovation mechanism that determines the direction of technological change (Rosenberg, 1976). In this model, the focusing devices correspond to different pricing schemes that determine the incentives for innovation. The first type of focusing device, the productivity-based pricing, is based on Harada (2013), so we will only sketch the main argument regarding this pricing scheme. Additionally, as an alternative, we also developa marginal productivity-based pricing scheme. Then, based on these two pricing schemes, we analyze how dynamic strategies are related to focusing devices and innovation probabilities.

\subsection{Firm}

Supposea firm produces output according to an o-ring type production function that was proposed by Kremer (1993). This production function incorporates the fact that mistakes in any of a series of tasks can dramatically reduce the product's value. In this paper, we suppose that the production function represents a technological system which consists of interrelated technology components, and these components are provided by specialized supplierswho should be distinguished from labor, below. As Rosenberg (1976) showed, bottlenecks or declines in quality in any of a series of technology components can dramatically reduce the product's value. Therefore, we adopt the o-ring type production function in this paper.

The firm produces the output $y$ with the production function

$$
y=A l^{\alpha} \prod_{i=1}^{m} q_{i}
$$

where $A$ denotes the productivity level and $l$ labor employed in this firm, $q_{(i)}$ is the technology component of type $i$, and $0<\alpha<1$. The right hand side of (1) does not refer to physical materials and parts, but represents technological interdependence among technology components as knowledge. Since knowledge has no quantity, it is assumed that one unit of each technology component is provided by a specialized supplier. The supplier of technology component of type $i$ receives a payment of $p\left(q_{(i)}\right)$ from the firm, which is differentiable with $p(0)=0$. To simplify the notation, each technology component as knowledge is produced without costs. The membership of these specialized suppliers in the firm is assumed to be fixed from the beginning.

$q_{(i)}$ is specified by a quality ladder (see, for example, Aghion \& Howitt, 1992)

$$
q_{(i)}=q^{\mu(i)}
$$

where $q>1$ and $\mu(i)$ takes positive integer values, representing the current quality level of a technology component of type $i$. It is assumed that $g$ types of technology components exist such that

$$
q_{(1)}>\cdots>q_{(s)}>\cdots>q_{(g)}
$$

We refer to the technology component of the highest quality, type 1 , as a core technology, whereas the technology component of the lowest quality, type $g$, is referred to as a bottleneck technology. 
The firm is risk-neutral and maximizes its current profits as

$$
\max _{\left\{q_{i}\right\}, l} A l^{\alpha} \prod_{i=1}^{g} q_{(i)}-\sum_{i=1}^{g} p\left(q_{(i)}\right)-w l
$$

where $w$ is the wage rate. Since each supplier provides one unit of technology component in this model, its factor price alone is subtracted in (4). The first order conditions (FOCs) with respect to $q_{(i)}$ and $l$ are respectively

$$
\begin{aligned}
& A l^{\alpha} \prod_{s \neq i}^{m} q_{i}=p^{\prime}\left(q_{(i)}\right) \\
& l=\left(\alpha A w^{-1} \prod_{s=1}^{g} q_{(s)}\right)^{\frac{1}{1-\alpha}}
\end{aligned}
$$

From(2), (5) and (6), we can derive

$$
p^{\prime}\left(q_{(i)}\right)=\left(\alpha^{\alpha} A w^{-\alpha}\right)^{\frac{1}{1-\alpha}} q_{(i)}{ }^{-1+\frac{\sum_{s}}{(1-\alpha) \mu((s)}}
$$

Assume that the firm earns zero profits due to perfect competition. Then, integrating (7) yields the factor price schedule as (Note 2).

$$
\begin{gathered}
p\left(q_{(i)}, \theta(i)\right)=(1-\alpha) \theta(i) y \\
\theta(i)=\frac{\mu(i)}{\sum_{s=1}^{g} \mu(s)}
\end{gathered}
$$

We refer to (8) as the productivity-based pricing.

\subsection{Productivity-Based Pricing}

The quality improvement for each technology component within the firm is assumed to be endogenously realized by specialized suppliers. Denote the amount of R\&D investment by $e$. With this R\&D level, the probability of quality improvement from $\mu(i)$ to $\mu(i)+1$ which is realized in the next period is given by $t(e)$ with $\partial \imath / \partial e>0$ and $\partial^{2} \imath / \partial e^{2}<0$.

To keep the model as simple as possible without loss of generality, we assume that in each period, each specialized supplier makes an R\&D investment to maximize the next period's profits, $p$. Moreover, we assume $\mathrm{R} \& \mathrm{D}$ investments made by other suppliers are correctly predicted by all suppliers in the firm. This implies the correct prediction of $y$ and $\sum \mu(s)$ in the next period. Then, the expected profits of quality improvement are

$$
V\left(q_{(i)}, e\right)=(1+r)^{-1} \iota(e) E p\left(q_{(i)}, \theta(i) \mid \mu(i)+1\right)-e
$$

where $r$ and $E$ denote the interest rate and expectation operator, respectively. $E p(\cdot)$ is the conditional expected price received from the firm when $\mu(i)+1$ is realized in the next period.

The FOC with respect to $e$ is

$$
(1+r)^{-1} \iota^{\prime}(e) \operatorname{Ep}\left(q_{(i)}, \theta(i) \mid \mu(i)+1\right)=1
$$

Denote the Nash equilibrium R\&D level for the current quality level of $q_{(s)}$ as $e^{*}\left(q_{(s)}\right)$. Then, obviously, higher quality leads to more R\&D investment, i.e., $e^{*}\left(q_{(1)}\right)>\cdots>e^{*}\left(q_{(g)}\right)$. This implies that quality 
improvement is more frequently observed at the higher end of the quality ladder. Thus technological divergence is magnified over time among different firms and among different components within a firm.

\subsection{Marginal Productivity-Based Pricing}

While this pricing scheme generates core-driven innovation, a number of case studies suggest that innovation proceeds to remove reverse salients, rather than further improving core technologies (Geyer \& Davies, 2000; Prencipe, 2000; Fransman, 2001; Mulder \& Knot, 2001; Christiansen \& Buen, 2002; Markard \& Truffer, 2006; Dedehayir \& Mäkinen, 2008). The reverse salients or bottlenecks are the areas of imbalance in the system. They are caused by the uneven growth of the system's components and prevent the further advance of the system. To overcome a reverse salient, it is crucial that firms are capable of "defining reverse salients as a set of critical problems" (Hughes, 1983). Thus, the productivity-based pricing scheme, though derived from optimization, is not consistent with these arguments.

As an alternative to the productivity-based pricing scheme, we will formalize reverse salients as a focusing device. In this model, reverse salients correspond to bottleneck technologies that have the highest marginal productivity of innovation. When the reward from innovation is proportional to marginal productivity of innovation, it must satisfy

$$
p\left(q_{(i)}, \theta(i)\right) \propto \frac{y}{q_{(i)}}
$$

Since a firm is assumed to earn nothing, and only specialized suppliers get positive profits, theprice satisfying (12) for all technology components is

$$
p\left(q_{(i)}, \theta(i)\right)=(1-\alpha) \frac{q_{(i)}^{-1}}{\sum_{s=1}^{g} q_{(s)}^{-1}} y
$$

This implies $p\left(q_{(1)}, \theta(1)\right)<\cdots<p\left(q_{(g)}, \theta(g)\right)$.

Then, the $i$ thspecialized suppliers makes R\&D investment to maximize

$$
(1+r)^{-1} \iota(e) \operatorname{Ep}\left(q_{(i)}, \theta(i) \mid \mu(i)+1\right)-e
$$

Obviously, $e^{*}\left(q_{(1)}\right)<\cdots<e^{*}\left(q_{(g)}\right)$ holds. We refer to (13) as the marginal productivity-based pricing. Then, innovation proceeds to improve bottleneck technologies. This pattern of innovation is consistent with the focusing device demonstrated by Rosenberg (1976) and Hughes (1983).

\section{Dynamic Strategies and Focusing Devices}

\subsection{Optimal Focusing Devices and Dynamic Efficiency}

In this section, we will examine the optimal relation between focusing devices and dynamic strategies based on the model of focusing device. For this purpose, we slightly modify the production function in (1) as

$$
y=A l^{\alpha} \prod_{i=1}^{m} q_{(i)}^{c} \prod_{j=1}^{n} q_{(j)}^{v}
$$

where $q^{c}$ and $q^{v}$ represents a technology component that primarily raises cost advantage (productivity) and customer value (quality), respectively. Define the relative advantage of quality as (Note 3)。

$$
\Lambda \equiv \prod_{j=1}^{n} q_{(j)}^{v} / \prod_{i=1}^{m} q_{(i)}^{c}
$$


According to this specification, the quality-improving strategy is to primarily enhance $\prod_{j=1}^{n} q_{(j)}^{v}$ with $\Lambda>1$, whereas the cost-reducing strategy gives priority to the improvement of $\prod_{i=1}^{m} q_{(i)}^{c}$ with $\Lambda<1$. The hybrid strategy aims for growth balanced between the two to attain $\Lambda=1$.

The efficiency of focusing devices critically depends on these dynamic strategies. In the quality-improving and cost-reducing strategies, core-driven innovation should be adopted because of the unbalanced nature of the corresponding innovation trajectories. For example, if the quality-improving strategy is pursued, $\Lambda>1$ should be realized at some point in time and maintained afterwards. Suppose the marginal productivity-based pricing is adopted when $\Lambda>1$. The innovative efforts willthen be devoted towards cost-reducing innovations. This reduces the value of $\Lambda$. As a result, itsinnovation trajectory follows that of a hybrid strategy. Obviously, the marginal productivity-based pricing scheme should be adopted to maintain its innovation trajectory near $\Lambda=1$ over time. Thus, when a dynamic strategy is implemented with the efficient focusing device, it achieves a higher innovation probability than using inappropriate focusing devices. Hence, we can obtain the following result:

PROPOSITION 1: It is efficient that a hybrid strategy adopts the marginal productivity-based pricing, while quality-improving and cost-reducing strategies adopt the productivity-based pricing.

As we have seen in Section 2, while a hybrid strategy in a static sense might lead to competitive disadvantage according to Porter (1980), it outperforms both cost-reducing and quality-improving strategies in a dynamic sense. We should not, therefore, overemphasize differentiation and cost leadership as the sources of competitive advantage. Rather, these generic competitive strategies depict patterns of competitive advantage from the ex-post perspective. In other words, we should not confuse cause and effect by extrapolating the source from the observed pattern of competitive advantage. The model in this paper suggests that the source of competitive advantage is using dynamic strategies, the efficiency of which is in turn accounted for stochastically by the underlying focusing devices. Thus, whereas the "stuck-in-the middle" static strategy should be dismissed from the ex-post perspective, its dynamic counterpart—a hybrid strategy — must be recommended with the marginal productivity-based pricing scheme from the ex-ante perspective.

In a number of industries, innovation proceeds to improve quality and reduce costs simultaneously. For example, when the Bell Punch Company developed the world's first electronic desktop calculators, ANITA Mk VII and ANITA Mk 8 in 1961, the price was approximately $\$ 1,000$. After more than fifty years, theprice of a low-end pocket calculator is now less than $\$ 10$ while the quality and performance have improved significantly. Similar simultaneous improvements in quality and cost performance can be observed in many high tech products such as computers, cell phones, and audio and visual equipment. This strongly suggests that a hybrid strategy should be implemented over time.

\subsection{Strategic Convergence and Path-Dependency}

According to the strategic convergence pointed out in Section 2, both quality-improving and cost-reducing strategies should shift to a hybrid one at some point in the future to gain dynamic competitive advantage. This shift is sometimes delayed if changes in the focusing device cause some switching costs. A change in the pricing schemes necessitates renegotiating with specialized suppliers, modifying, and renewing contracts. This process takes time and sometimes requires irreversible investment. In particular, a productivity-based pricingscheme tends to generate and expand technology divergence among technology components over time. This self-reinforcing nature makes it even more costly to change the focusing devices, because core suppliers lose the most and this loss is larger when the quality level is more important. The compensation for this loss also constitutes part of the irreversible investment.

PROPOSITION 2: When the productivity-based pricing scheme is employed for either quality-improving or cost-reducing strategies, the strategic shift to a hybrid strategy is likely to be delayed, owing to its self-reinforcing nature.

Thus, the strategic convergence causes a misalignment between dynamic strategies and focusing devices. This result could account for the loss of future competitive advantage because of success in gaining current competitive advantage. Success is the mother of failure in this case. However, if the firm gains competitive advantage from a hybrid strategy with a marginal productivity-based pricing scheme, this misalignment never occurs. 
In reality, even if the firm adopts the marginal productivity-based pricing scheme, a misalignment between dynamic strategies and focusing devices could take place, becausethe recognition of reverse salients is not as simple as this model suggests. For example, in their empirical study of the PC gaming industry, Dedehayir \& Mäkinen (2008) discussed how game developers, to guarantee success, tend to launch products with a focus on factors other than technological bottlenecks. They pointed out that the ability to gauge the magnitude of bottleneck severity in technological sub-systems is likely to increase innovation performance. This argument suggests that conventional incentive schemes do not provide information that reflects marginal productivity of innovation. Thus, a discrepancy linked to the marginal productivity-based pricing scheme tends to arise in the process of innovation.

The R\&D resource allocation literature has indicated the potential difficulty of the management of focusing devices or incentive schemes in R\&D (see Kavadias \& Chao, 2007 for a survey). According to Shane and Ulrich (2004), a substantial body of research has been focused on the question of which innovation projects to pursue. However, these models have not been used much in practice. Chao and Kavadias (2008) argued that R\&D portfolio considerations at the strategic level remain for the most part qualitative, and the need for a solid theoretical framework is imperative. They proposed the model of the strategic buckets problem, but the effective use of that requires a deeper understanding of environmental complexity and environmental instability. This requirement suggests real practical difficultiesin managing the R\&D portfolio effectively in a firm.

Therefore, one critical aspect of technology management, along with dynamic strategies, is correcting the misalignment between dynamic strategies and focusing devices. Even though irreversible investment in changing focusing devices may not be justifiable in terms of current profits, this change must be implemented as soon as the strategic shift is decided. The temporal loss due to irreversible investment can be justified from a dynamic perspective. Hence, the firm must keep an eye on the focusing device underlying the current innovation trajectory, and if some misalignment exists, the optimal focusing device should be developed and implemented immediately. Otherwise, the firm is likely to lose the next round of competition to competitors with optimal focusing devices.

From this perspective, we could shed new light on the innovator's dilemma highlighted by Christensen (1997). Disruptive technologies are characterized by low quality and high cost performance. As long as the quality remains low, the innovator's dilemma does not take place. However, innovation in the disruptive technology leads to rapid improvement in quality, and subsequent replacement of current sustaining technologies. Firms failing to adopt disruptive technologies are therefore eventually driven out of business. This dynamic of industry and technologies implies that quality and cost simultaneously improve over time, despite the fact that discontinuities between disruptive and sustaining technologies exist. To avoid the innovator's dilemma, our result suggests that the firm's dynamic strategy should converge to a hybrid one with the marginal productivity-based pricing scheme. Otherwise, the firm cannot overcome the innovator's dilemma in the long run.

\section{Conclusions}

This paper has analyzed the properties of dynamic strategies and underlying focusing devices and showed how they are related to competitive advantage. This analysis shares the view of Teece et al. (1997) that competitive advantage should be accounted for by some dynamics of the firm together with innovation, rather than an industry position that is nothing but a result of such dynamics. However, instead of using the conceptual framework and terminology of their dynamic capabilities approach, we have elaborated on the relationship between dynamic strategies and focusing devices.

The dynamic strategies correspond to innovation trajectories and their current positions determine competitive advantage. Because competitive advantage is the result of the underlying controlled stochastic processes, innovation probability maximization that is enabled by adopting an appropriate focusing device does not necessarily lead to success in gaining sustainable competitive advantage. Nevertheless, the law of large numbers ensures that the firm with the highest innovation probability gains competitive advantage many times and succeeds in attaining resilience to competitive disadvantage. Under highly volatile environments, the firm should abandon the illusion of sustainable competitive advantage. Instead, it should shift its focus to the cause of competitive advantage, that is, dynamic strategies and focusing devices, to achieve resilience to competitive disadvantage. This is not because failure is the mother of success, but because current success can be the mother of future failure, particularly when there is a misalignment between dynamic strategies and focusing devices, as shown in Proposition 2. The current practices of strategic and technology management should therefore be 
modified in favor of innovation probability maximization, with more emphasis on innovation trajectories and focusing devices.

This result also sheds new light on the vast literature examining incumbents' willingness to undertake radical innovation (Tushman \& Anderson, 1986; Reinganum, 1989; Ghemawat, 1991; Leonard-Barton, 1992; Ai et al., 1993; Henderson, 1993; Christensen \& Bower, 1996; Gatignon et al., 2002; Turut \& Ofek, 2013). The common thread underlying this literature is that radical innovation cannibalizes incumbents' current sales and assets. Therefore, only those who exhibit sufficient willingness to accept the cannibalization can sustain dynamic competitive advantage (Druehl \& Schmidt, 2008).

Our result complements, rather than substitutes, this literature in two notable respects. First, while most of the models in the literature assume only two types of innovation, radical and incremental, the model in this paper allows for multiple technologies and explicitly analyzes different mechanisms (focusing devices) that guide the direction of innovation. Second, our result explicitly shows the relative dynamic efficiency of a hybrid strategy, instead of analyzing incentives to undertake either radical or incremental innovation. If radical and incremental innovation trajectories are incorporated into the model in this paper, we conjecture that the highest innovation probability will be realized somewhere between the two trajectories, in line with the balance shown by Chao \& Kavadias (2008). We are interested in examining which trajectory or innovation generates a higher innovation probability over time. We believe that the relative evaluation of different innovation trajectories in terms of innovation probability also constitutes an important research topic in the innovation strategy literature.

From the perspective of innovation probability maximization, we can draw several conclusions. First, the firm should determine the appropriate direction of innovation trajectories, rather than a competitive position, compared with its competitors. In other words, the focus should shift from a point to line. Second, once an innovation trajectory is determined, the firm should identify its current focusing device and examine whether it is congruent with the desired dynamic strategy. If some misalignment exists, the optimal focusing device should be devised. Finally, over the long term, the firm should adopt a hybrid strategy, although targeted paths might consist of the alternation of quality-improving and cost-reducing strategies under unbalanced and antagonistic growth paths.

\section{Acknowledgements}

I would like to thank seminar participants at Kyoto University, Osaka University, and Kobe University for very useful comments and suggestions. The comments by two anonymous referees are also highly appreciated. This work was supported by JSPS KAKENHI Grant Number 26380506. Any errors in this paper are the sole responsibility of the author.

\section{References}

Aghion, P., \& Howitt, P. (1992). A model of growth through creative destruction. Econometrica, 60, 323-351.

Ali, A., Kalwani, M. U., \& Kovenock, D. (1993). Selecting product development projects: pioneering versus incremental innovation strategies. Management Science, 39, 255-274. http://dx.doi.org/10.1287/mnsc.39.3.255

Barreto, I. (2010). Dynamic capabilities: a review of past research and an agenda for the future. Journal of Management, 36, 256-280. http://dx.doi.org/10.1177/0149206309350776

Becker, G. (1991). A Treatise on the Family. Cambridge: Harvard University Press.

Branderburgearn, A. M., \& Stuart, H. W. (1996). Value-based business strategy. Journal of Economics and Management Strategy, 5, 5-24.

Chao, R. O., \& Kavadias, S. (2008). A theoretical framework for managing the new product development portfolio: when and how to use strategic buckets. Management Science, 54, 907-921. http://dx.doi.org/10.1287/mnsc. 1070.0828

Christensen, C. M. (1997). The Innovator's Dilemma: When New Technologies Cause Great Firms to Fail. Boston: Harvard Business School Press.

Christensen, C. M., \& Bower, J. L. (1996). Customer power, strategic investment, and the failure of leading firms. Strategic Management Journal, $17, \quad$ 197-218. http://dx.doi.org/10.1002/(SICI)1097-0266(199603)17:33.0.CO;2-U 
Christiansen, A. C., \& Buen, J. (2002). Managing environmental innovation in the energy sector: the case of photovoltaic and wave power development in Norway. International Journal of Innovation Management, 6, 233-256. http://dx.doi.org/10.1142/S1363919602000586

David, P. A. (1975). Technical Choice, Innovation and Economic Growth. Cambridge: Cambridge University Press.

Dedehayir, O., \& Mäkinen, S. J. (2008). Dynamics of reverse salience as technological performance gap: an empirical study of the personal computer technology system. Journal of Technology Management \& Innovation, 3, 55-66. http://dx.doi.org/10.4067/S0718-27242008000100006

Dosi, G. (1982). Technological paradigms and technological trajectories. Research Policy, 11, 147-162.

Druehl, C. T., \& Schmidt, G. M. (2008). A strategy for opening a new market and encroaching on the lower end of the existing market. Production and Operations Management, 17, 44-60. http://dx.doi.org/10.3401/poms.1070.0002

Fransman, M. (2001). Analysing the evolution of industry: the relevance of the telecommunications industry. Economics of Innovation and New Technology, 10, 109-140. http://dx.doi.org/10.1080/10438590100000006

Gatignon, H., Tushman, M. L., Smith, W., \& Anderson, P. (2002). A structural approach to assessing innovation: construct development of innovation locus, type, and characteristics. Journal of Marketing, 48, 1103-1122. http://dx.doi.org/10.1287/mnsc.48.9.1103.174

Geyer, A., \& Davies, A. (2000). Managing project-system interfaces: case studies of railway projects in restructured UK and German markets. Research Policy, 29, 991-1013. http://dx.doi.org/10.1016/S0048-7333(00)00116-5

Ghemawat, P. (1991). Market incumbency and technological inertia. Marketing Science, 10, 161-71.

Harada, T. (2010). Path-dependent economic growth with technological trajectory. Economics of Innovation and New Technology, 19, 521-538. http://dx.doi.org/10.1080/10438590903166412

Harada, T. (2013). Focusing device as innovation mechanism and cluster growth. Economics of Innovation and New Technology. http://dx.doi.org/ 10.1080/10438599.2013.806407

Henderson, R. (1993). Underinvestment and incompetence as responses to radical innovation: evidence from the photolithographic alignment equipment industry. Rand Journal of Economics, 24, 248-270. http://dx.doi.org/10.2307/2555761

Kavadias, S., \& Chao, R. O. (2007). Resource allocation and new product development portfolio management. In C. H. Loch \& S. Kavadias (Eds.), Handbook of New Product Development Management. Oxford: Elsevier/Butterworth-Heinemann.

Kremer, M. (1993). The o-ring theory of economic development. Quarterly Journal of Economics, 108, 551-575. http://dx.doi.org/10.2307/2118400

Leonard-Barton, D. (1992). Core capabilities and core rigidities: a paradox in product development. Strategic Management Journal, 13, 111-126. http://dx.doi.org/10.1002/smj.4250131009

Markard, J., \& Truffer, B. (2006). Innovation processes in large technical systems: market liberalization as a driver for radical change? Research Policy, 35, 609-625. http://dx.doi.org/10.1016/j.respol.2006.02.008

Mulder, K., \& Knot, M. (2001). PVC plastic: ahistory of systems development and entrenchment. Technology in Society, 23, 265-286. http://dx.doi.org/10.1016/S0160-791X

Nelson, R. R., \& Winter, S. G. (1977). In search of useful theory of innovation. Research Policy, 6, 36-76. http://dx.doi.org/10.1016/0048-7333(77)90029-4

Porter, M. E. (1980). Competitive Strategy: Techniques for Analyzing Industries and Competitors. New York: Free Press.

Porter, M. E. (1996). What is strategy? Harvard Business Review, November-December, 61-78.

Prencipe, A. (2000). Breadth and depth of technological capabilities in Cops: the case of the aircraft engine control system. Research Policy, 29, 895-911. http://dx.doi.org/10.1016/S0048-7333(00)00111-6

Reinganum, J. F. (1989). The timing of innovation: research, development, and diffusion. In R. Schmalensee \& R. D. Willig (Eds.), Handbook of Industrial Organization. Amsterdam: Elsevier Science Publishers B.V. 
Rosenberg, N. (1976). Perspectives on Technology. Cambridge: Cambridge University Press.

Sahal, D. (1985). Technological guideposts and innovation avenues. Research Policy, 14, 61-82. http://dx.doi.org/10.1016/0048-7333(85)90015-0

Shane, S. A., \& Ulrich, K. T. (2004). 50th anniversary article: technological innovation, product development, and entrepreneurship in Management Science. Management Science, 50, 133-144. http://dx.doi.org/10.1287/mnsc.1040.0204

Teece, D. J., Pisano, G., \& Shuen, A. (1997). Dynamic capabilities and strategic management. Strategic Management Journal, $18, \quad 509-533$. http://dx.doi.org/10.1002/(SICI)1097-0266(199708)18:7<509::AID-SMJ882>3.0.CO;2-Z

Turut, O., \& Ofek, E. (2012). Innovation strategy and entry deterrence. Journal of Economics \& Management Strategy, 21, 583-631. http://dx.doi.org/10.1111/j.1530-9134.2012.00342.x

Tushman, M. L., \& Anderson, P. (1986). Technological discontinuities and organizational environments. Administrative Science Quarterly, 31, 439-465. http://dx.doi.org/10.2307/2392832

Wernerfelt, B. (1984). Resource-based view of the firm. Strategic Management Journal, 5, 171-180. http://dx.doi.org/10.1002/smj.4250050207

Williamson, O. E. (1999). Strategy research: governance and competence perspectives. Strategic Management Journal, 20 , $1087-108$. http://dx.doi.org/10.1002/(SICI)1097-0266(199912)20:12<1087::AID-SMJ71>3.0.CO;2-Z

\section{Notes}

Note 1. Innovation trajectories have been discussed by a number of studies using different terms such as natural trajectories (Nelson \& Winter, 1977), technological trajectories (Dosi, 1982), technological guideposts (Sahal, 1985), and trajectory-sustaining vs. trajectory-disruptive innovation (Christensen \& Bower, 1996). In formal models, innovation trajectories were analyzed by David (1975) and Harada (2010). Although these studies differ in terms and analytical apparatus, they share the view that innovation proceeds in a path-dependent manner. As a result, once innovation trajectories are determined, they are less likely to change over time.

Note 2. This integration is made to derive the solution that satisfies(5)and zero profits. It is easy to check that solution (8) satisfies both. $p$ is strictly convex with respect to the $q$ that ensures an optimum exists in (4). It should also be noted that (8)depends on $\theta(i)$. From (5), it is easy to see $q_{(i)} p^{\prime}\left(q_{(i)}\right)=q_{(j)} p^{\prime}\left(q_{(j)}\right)$ holds. If $p$ is a function of $q_{(i)}$ alone, this equality is satisfied if and only if $q_{(i)}=q_{(j)}$. However, since $p$ also depends on $\theta(i), \quad q_{(i)} p^{\prime}\left(q_{(i)}, \theta(i)\right)=q_{(j)} p^{\prime}\left(q_{(j)}, \theta(i)\right)$ holds even if $q_{(i)} \neq q_{(j)}$.

Note 3. This model introduces quality and cost advantage as the dimensions of the product. This is because strategic management literature tends to emphasize these two aspects of the product as the determinants of competitive advantage (see for example, Brandenburger \& Stuart, 1996). However, the results of the model in this paper are not altered even if two different quality dimensions are introduced instead of quality and cost advantage.

\section{Copyrights}

Copyright for this article is retained by the author(s), with first publication rights granted to the journal.

This is an open-access article distributed under the terms and conditions of the Creative Commons Attribution license (http://creativecommons.org/licenses/by/3.0/). 